ARTIGO

\title{
Contribuições ao projeto de uma pedagogia fenomenológico-hermenêutica:
}

Ricardo Pedroza Vieira' (D

\section{RESUMO}

O artigo fornece uma introdução filosófica à tradição da fenomenologia hermenêutica e um panorama do projeto de uma pedagogia fundada nas questões centrais dessa tradição. A seguir, por meio de um diálogo com Paulo Freire e de relatos de experiência do autor, procura refletir sobre o problema de como orientar-se em meio ao processo de ensino-aprendizagem.

PALAVRAS-CHAVE

fenomenologia; pedagogia; hermenêutica.

'Colégio Pedro II, Rio de Janeiro, RJ, Brasil. 


\section{CONTRIBUTIONS TO THE PROJECT OF A PHENOMENOLOGICAL-HERMENEUTICAL PEDAGOGY}

\section{ABSTRACT}

The article is a philosophical introduction to the tradition of phenomenology and hermeneutics and an outlook of the project of a pedagogy rooted on the main issues of this tradition. It also builds a reflection on the problem of orientation amidst the teaching-learning process through a dialog with Paulo Freire and reports from the author's own experience.

KEYWORDS

phenomenology; pedagogy; hermeneutics.

\section{CONTRIBUCIONES AL PROYECTO DE UNA PEDAGOGÍA FENOMENOLÓGICA-HERMENÉUTICA}

\section{RESUMEN}

El artículo proporciona una introducción filosófica a la tradición de la fenomenología hermenéutica y una visión general del proyecto pedagógico fundado en los temas centrales de esta tradición. Luego, a través de un diálogo con Paulo Freire y los informes de la experiencia del autor, busca reflexionar sobre el problema de cómo orientarse en medio del proceso de enseñanza-aprendizaje.

PALABRAS CLAVE

fenomenología; pedagogía; hermenéutica. 


\section{INTRODUÇÃO}

Este ensaio pretende atingir dois objetivos principais, que se refletem em sua estrutura. Primeiramente, proporcionar uma introdução filosófica às questões da pedagogia fenomenológico-hermenêutica, acessível e informativa tanto para educadores em geral como para estudantes de filosofia, fornecendo um panorama breve do contexto histórico e bibliográfico do tema. Além disso, que possa acenar para a possibilidade de fazer uma experiência: compreender a prática pedagógica como uma prática com sua dimensão própria de pensamento. Não redutível, portanto, a nenhuma teoria pedagógica ou filosófica. Trata-se, então, de um convite ao cultivo de uma sensibilidade, uma disposição afetiva e uma disponibilidade para a reflexão concentrada sobre o que é vivido na prática pedagógica. As implicações destas afirmações iniciais e os problemas que elas carregam serão tema que atravessará todo o ensaio.

Em seguida, pretendemos tentar oferecer uma contribuição ao projeto de uma pedagogia fenomenológico-hermenêutica por intermédio da colocação da questão: como orientar-se em meio ao processo de ensino-aprendizagem? Abordaremos a questão por meio de um diálogo entre a fenomenologia hermenêutica e algumas indicações provenientes do pensamento de Paulo Freire. Também utilizaremos como suporte alguns relatos da experiência do autor como professor no Colégio Pedro II, campus Engenho Novo II, no Rio de Janeiro.

\section{UMA BREVE INTRODUÇÃO À FENOMENOLOGIA HERMENÊUTICA}

O termo "fenomenologia" aparece, por vezes, nos campos das ciências da natureza ou da medicina indicando uma descrição objetiva de determinados dados empíricos, que não devem ser distorcidos pela subjetividade do observador. Em filosofia, contudo, a palavra geralmente se associa à escola de pensamento fundada por Edmund Husserl (1859-1938), preocupada, inicialmente, em resolver o problema da relação entre sujeito e objeto. Martin Heidegger (1889-1976), discípulo de Husserl, concluirá posteriormente que os próprios conceitos de sujeito e objeto são insuficientes, propondo os novos conceitos de Dasein ("presença" ou "ser-aî") e ser-no-mundo. A tensão entre esses pensadores inspira uma tradição multifacetada. Nosso foco nesta introdução não será fornecer detalhamento histórico desses acontecimentos, mas procurar, a partir de referências dos pensadores da escola da fenomenologia, construir um acesso a alguns temas centrais, conectados aos problemas pedagógicos que temos em vista ulteriormente ${ }^{1}$.

Um desses pensadores, Merleau-Ponty (1908-1961), procurou certa vez definir a fenomenologia assim: "trata-se de descrever, não de explicar nem de analisar” (Merleau-Ponty, 2011, p. 3). Essa definição diferencia coisas que costumamos associar. "Explicar" significa procurar relações causais e padrões de regularidade,

1 Uma boa introdução filosófica à fenomenologia, com mais detalhes históricos e particularidades de cada autor, pode ser encontrada em Cerbone (2014). 
ao passo que "analisar" significa remeter um dado a um conceito do qual ele seja um caso. Assim, um médico que toma o pulso de um paciente não está interessado, digamos, no aspecto musical do ritmo da pulsação, mas em coletar um dado previamente orientado pelo conceito de pressão arterial, que por sua vez remete ao ritmo cardíaco enquanto causa da pulsação e a certos padrões de regularidade desse ritmo que se encontram associados a potenciais condições de saúde. Para o olhar científico, descrever é precisamente explicar e analisar. Para isso, contudo, esse olhar precisa depurar, filtrar, selecionar. Certos elementos da experiência ficam de fora da descrição, porque não correspondem ao interesse em explicar e analisar. O que é isso que "ficou de fora"? Como é essa experiência anterior a uma "fenomenologia científica"? Como é possível formar uma perspectiva científica e transitar entre diferentes tipos de olhares e de experiências sobre o mundo? Essas são perguntas centrais da fenomenologia filosófica. Assim, Merleau-Ponty (2011, p. 2) também afirmou que a fenomenologia é um "estilo", um certo "método". Essas duas palavras remetem à maneira pela qual a descrição vai se construindo e se orientando ao longo de seu processo. Para o médico ou o cientista, há certos dados que podem ser descritos como a "pulsação" de um "paciente" porque essa descrição é orientada por um método científico. Outros modos de descrição devem supor, portanto, outros métodos. Por exemplo: um poeta também poderia descrever alguma coisa sobre a pulsação - que talvez então nem mais pudesse ter esse nome. Seria o olhar do poeta algo completamente subjetivo, fantasioso e arbitrário, que não requer nenhum cuidado ou dedicação? Ou envolve também algum tipo de concentração, escolhas, tentativas e erros, reflexões, reformulações - em suma, algum tipo de método? O que dizer, então, do olhar leigo, cotidiano e talvez até entediado de alguém que, por acaso, em meio a uma espera qualquer, ao apoiar uma mão sobre a outra sente ali um pulso? Será esse mais simples dos olhares o único desprovido de método?

Uma coisa se pode logo notar: um mesmo fenômeno pode aparecer de diferentes maneiras. A cada vez o fenômeno se mostra à luz de um certo sentido. Fenômeno é sempre, de alguma forma, sentido. $\mathrm{O}$ médico sente a pressão arterial. Ele não sente um dado tátil bruto e neutro que, em um segundo momento, ele associa a certo conceito. Seu sentir já é sentido: pressão alta, potencial de hipertensão, risco cardíaco. Foi preciso aprender a olhar as coisas assim, treinar para saber sentir assim. Também o leigo, que aparentemente nada sente ao tocar o pulso a não ser uma vibração desinteressante que não lhe diz nada e é logo esquecida, encontrou nesse sentir o sentido do tédio e do desinteresse. Pois mesmo a "falta de sentido" ou qualquer coisa semelhante é uma experiência de sentido, sob o modo da ausência. Há algo cuja falta sensibiliza de alguma maneira. A relação de alguém com o tédio e o desinteresse enquanto fenômenos que se apresentam em sua vida, os hábitos e as reações que foram construídos a esse respeito, também estarão atuantes como orientações "metodológicas" nesse momento. Em todo caso, separar aquela vibração do interesse ou desinteresse do ser humano que a sente, e assim pensá-la como um dado bruto sem nenhum sentido e que só posteriormente recebe um sentido, é uma abstração da experiência - e de um tipo altamente problemático. Afinal, como imaginar alguma coisa absolutamente sem sentido? 
A fenomenologia procura descrever, não explicar ou analisar. Significa: procura descrever o sentido, tal como aparece ou se mostra em cada caso, e não apenas o sentido próprio ao olhar científico. Para ser mais preciso, Merleau-Ponty (2011, p. 17) afirma que Husserl já havia definido a fenomenologia como uma descrição da "gênese do sentido", isto é, seu processo de vir a ser. Por isso, é um método e um estilo de pensar, cuja orientação é acompanhar o ritmo desse processo que visa descrever. Fenomenologia é "sentir o pulso" do sentido.

Conforme se descobria e se assumia como descrição da gênese do sentido, a fenomenologia foi se aproximando historicamente de uma outra tradição filosófica: a hermenêutica. Essa palavra é familiar ao direito e à teologia. Para essas disciplinas, hermenêutica significa técnica de interpretação de textos, que se pode aplicar, por exemplo, à interpretação de uma lei ou um texto sagrado. Desde Schleiermacher (2009), a hermenêutica começou a ganhar envergadura filosófica à medida que se deu conta de que qualquer técnica de interpretação de textos precisa se fundamentar em alguma compreensão mais elaborada a respeito da linguagem e da comunicação. Uma dificuldade que logo se coloca quando se procura interpretar um texto é a evidência de que ele foi escrito por alguém com experiências muito próprias e distintas daquelas do leitor, afetadas por um contexto diferente, outra circunstância histórica ou pelo modo de dizer de outra língua. Ler um autor antigo torna mais visível o jogo de diferenças que opera na comunicação e que, contudo, também se encontra em ação e gerando dificuldades mesmo na comunicação mais cotidiana entre pessoas próximas. Não obstante, ao tentar entender o texto ou a fala do outro, encontramo-nos partilhando também algo em comum — seja a língua, a história, ou ao menos a condição humana, pois, "se o que é para ser compreendido fosse completamente estranho àquele que deve compreender, e não houvesse nada de comum entre ambos, então não haveria ponto de contato para a compreensão" (Schleiermacher, 2009, p. 31).

A hermenêutica investiga de que maneiras é possível tentar se aproximar de um texto estranho, que não é claro de imediato, mas que requer certo esforço metodológico para vir a fazer sentido plenamente. Trata-se do desenvolvimento de métodos para ir ao encontro de sentidos que exigem desenvolvimento interpretativo. Assim, é fácil perceber a afinidade entre fenomenologia e hermenêutica. Elas convergem à medida que o texto que se quer interpretar é a própria experiência, porque experiência é gênese de sentido. A determinação conceitual dessa aproximação foi dada decisivamente no $§ 7$ de Ser e tempo (Heidegger, 2006, p. 65-78) enquanto vinculada, primeiramente, a uma analítica existencial e, ulteriormente, ao problema da ontologia. Significa que a tarefa da fenomenologia hermenêutica é, antes de mais nada, existencial, isto é, concernente ao caráter humano de toda experiência e ao problema do que significa ser humano, para, a partir daí, poder levantar problemas sobre nossas possibilidades de descrever e compreender a realidade ${ }^{2}$.

2 Uma boa introdução filosófica à hermenêutica, com mais detalhes históricos, particularidades de cada autor, e informações sobre sua aproximação com a fenomenologia, pode ser encontrada em Schmidt (2014). 
Se compreendermos o vínculo primário da fenomenologia hermenêutica com a existência humana, poderemos prosseguir para compreender a conexão que esse horizonte filosófico pode ter com a educação. Pois a educação deve permitir aprender a dialogar, seja com outros seres humanos ou com as divergências no interior de si mesmo. Trata-se de pôr em diálogo experiências para interpretá-las e ser capaz de formar e desenvolver diferentes olhares sobre o mundo, que por sua vez descobrem sentidos novos. É o que acontece quando, por exemplo, se procura ouvir um professor de química que procura mostrar a possibilidade de olhar uma porção de sal, não como aquele objeto cotidiano que se usa irrefletidamente, mas como um composto de certas combinações de átomos, propensas a certos tipos de reações. Trata-se de outro olhar, que é preciso treinar para adquirir, e por cujo intermédio se pode descobrir sentidos inesperados no mundo à volta. Como pode o professor ensinar a cultivar o olhar para a gênese de um novo sentido para as coisas - por exemplo, o sentido do interesse científico? Pois, apesar de impor a necessidade de cultivar um olhar objetivo e impessoal, a ciência é um interesse humano! Ensinar interesse certamente é algo bem diferente de ensinar um mero conjunto de informações, de procedimentos ou de técnicas, de modo burocrático — também é algo bem mais difícil e de sucesso mais arriscado. Pois o professor só poderá ensinar interesse por um outro olhar se também puder aprender interesse pelo que acontece enquanto ensina e pelo olhar do estudante a quem se dirige, carregado de outras experiências das quais o professor nada sabe. Para ser capaz de ensinar interesse, não basta apenas ter interesse pelo que se ensina. $O$ professor precisa se interessar também pelo aprender enquanto um fenômeno que desafia sua compreensão. Olhando apenas para o que quer ensinar e não também para o próprio ensinar, o professor, ainda que bem-intencionado e brilhante, acabará por dar aulas "para as paredes". Tenderá a ver as dificuldades ou o desinteresse dos alunos como algo ultrajante e desprezível e a privilegiar apenas aquele que por acaso demonstre talento e interesse espontâneos. Essa postura parece menos problemática quando professor e alunos são todos já pesquisadores e estudiosos em uma aula de pós-graduação, e o interesse pelo que é discutido já se encontra pressuposto. Contudo, essa não é uma situação exemplar para toda circunstância pedagógica, e sim excepcional. Por isso, é fácil para um professor, formado na universidade para ser um pesquisador, querer ser sempre apenas pesquisador e supor que ser professor é alguma coisa menor e secundária, e que cabe ao aluno fazer sozinho todo o trabalho pedagógico, até mesmo quando for uma criança ou um adolescente. Esse professor terá sempre grandes dificuldades em lidar com qualquer público que não seja previamente muito interessado.

De um ponto de vista axiológico, essas reflexões, talvez a princípio aparentemente triviais, nos conduzem a um paradoxo. Pois implicam que o aprender não pode ser tomado apenas como um objeto científico por parte das ciências da educação e da cognição. De acordo com tudo que dissemos até aqui, aprender é participar da gênese de sentido, que constitui a experiência e possibilita novos olhares. Também o olhar científico há de ser aprendido e é parte do fenômeno em questão. Sendo parte do fenômeno a ser observado, esse olhar não pode abarcar o todo do aprender. O aprender é necessariamente multifacetado e transversal a toda a multiplicidade de olhares possíveis sobre o mundo, sem se limitar ao interior de nenhum deles em 
particular. Consequentemente, todo pensamento sobre o aprender, seja de caráter científico, filosófico, ou mesmo multidisciplinar, precisa necessariamente ser sempre mantido em suspenso e em questão enquanto algo incompleto e sujeito a uma modificação - proveniente do aprender. Todo educador e pensador da educação corre sempre o perigo de deixar-se encantar por algum reducionismo que o leve a comprimir o aprender nos limites daquilo que ele já julga saber - sua disciplina com suas especificidades, seu conhecimento de técnicas pedagógicas ou psicologia, suas experiências pessoais pregressas etc. Ensinar não é um conteúdo que possa ser definitivamente aprendido. Em vez disso, só é possível ensinar à medida que se permanece aprendendo a ensinar. Tampouco há qualquer oposição entre o interesse em um conteúdo e o interesse em ensiná-lo. Pois, ao aprender um novo modo de ensinar algo, aquilo que é ensinado é novamente aprendido sob um aspecto ou por meio de um caminho que até então se desconhecia. O professor que procura aprender a ensinar ensina ao modo de um aprender compartilhado, pois aprende a cada vez sob outro aspecto ou caminho aquilo que já sabia, ou que julgava já saber. Guimarães Rosa (2001, p. 326) escreveu certa vez: "Mestre não é quem sempre ensina, mas quem de repente aprende". O ensinar "de sempre", procedimento rotineiro e já dominado, precisa ceder espaço à possibilidade de um "de repente" que torne o próprio ensinar um aprender.

Estas são as premissas gerais a serem aprofundadas e mais bem justificadas pelo projeto de uma pedagogia fenomenológico-hermenêutica. Agora, estamos em melhores condições de discutir este projeto.

\section{O PROJETO DE UMA PEDAGOGIA FENOMENOLÓGICO-HERMENÊUTICA}

Embora não pretendamos nos deter muito em uma abordagem histórica, é digno de nota mencionar a existência de uma pedagogia fenomenológica enquanto "uma fase do pensamento educacional da Europa Ocidental durante o período aproximado de 1940 a 1970” (van Manen, 1996, p. 39)3, irradiando-se principalmente a partir da Alemanha e da Holanda. Trata-se de uma tradição não apenas de investigação teórica, mas de aplicação prática de certas formulações do método fenomenológico à educação de crianças e adolescentes. De acordo com van Manen (1996), o pensamento central que caracteriza essa corrente é "uma diminuição da importância do papel da teorização abstrata para a compreensão da experiência humana" (van Manen, 1996, p. 41). Essa premissa se sustenta em uma distinção conceitual fundamental para toda a tradição da fenomenologia, cuja plena envergadura e implicações ainda são objeto de debate e investigação: aquela realizada nos $\S \S 9$ e 15 de Ser e tempo entre Vorbandenheit e Zuhandenheit, "ser simplesmente dado" e "manualidade" (Heidegger, 2006, p. 85-89; p. 114-121), ou experiência teórica e experiência pré-teórica (ou reflexiva e pré-reflexiva). Essa

3 Sempre que, como neste caso, o texto citado encontra-se em língua estrangeira, fornecemos versão em português com tradução nossa. 
distinção já encontrava-se ecoando sub-repticiamente em nosso texto até aqui, à medida que discernimos diferenças entre o olhar científico e outros olhares não científicos a respeito de um mesmo fenômeno. Porém, a ideia de uma diferença entre experiências teóricas e pré-teóricas é mais ampla. Antes de ver como essa diferença é apropriada pela pedagogia fenomenológica, precisaremos analisá-la mais detidamente.

Pense por um momento em alguma dessas experiências que lhe seja mais familiar: nadar, dirigir um carro, andar de bicicleta, lutar boxe, dar um drible no futebol. Nenhuma dessas atividades pode ser aprendida apenas lendo manuais, assistindo a aulas teóricas ou observando a performance de outros. Todas elas exigem treino, prática, experiência. Isso nunca equivale a uma mera aplicação de um padrão dado pela teoria. É verdade que um boxeador treina milhares de vezes uma mesma esquiva padronizada e um motorista iniciante treina a maneira de pisar na embreagem, frear e acelerar em uma curva segundo certa ordem, mas não para obter execução sempre exatamente igual. Também é preciso aprender a adaptar aquela atividade às circunstâncias. Perceber imediatamente, por exemplo, que o golpe do adversário veio em um ângulo um pouco estranho, ou que a pista tem uma aderência inesperada, e reagir antes de ser capaz de refletir ou raciocinar explicitamente sobre como ajustar aquela situação a um determinado planejamento ou teoria qualquer. Trata-se de uma reação às circunstâncias de uma ação que não se ajusta a uma reflexão ou planejamento, mas ao sentido dos fenômenos em questão, conforme este se mostra no desenrolar do acontecimento. Todo aquele treino não visava memorizar uma sequência de movimentos para repeti-la exatamente, mas sim a aquisição de um olhar concentrado capaz de acompanhar o sentido e a criatividade da ação. Se considerarmos o exemplo do futebol, podemos recorrer à ajuda de Nelson Rodrigues (2013, p. 50-51) para pensar sobre isto:

Garrincha não pensa, nem precisa pensar. [...] Nós pensamos todos os nossos atos. Não fazemos nada sem um penoso processo mental. Antes de atravessar a rua, ou de chupar um Chicabon, o homem normal é lacerado de dúvidas. Ele estaca diante da carrocinha amarela e, acometido de uma perplexidade hamletiana, pergunta, de si para si: - "Tomo ou não tomo o Chicabon? Talvez seja melhor não tomar o Chicabon. Ou devo tomar?” Em futebol, a mesma coisa. Ao praticar um reles arremesso lateral, o jogador esbanja um tempo precioso ao escolher o companheiro que deve receber a bola. $\mathrm{O}$ ser humano pensa demais e é pena, pois a vida é, justamente, uma luta corporal contra o tempo. Repito: - o ser humano vive pouco porque pensa muito. Ora, a máxima característica terrena de Garrincha é a seguinte: - ele não precisa pensar. E, por isso, porque não pensa, posso apontá-lo como a única sanidade mental do Brasil. [...] Resta perguntar: - se Garrincha não pensa, vive então de quê? Vive do instinto, da prodigiosa e instantânea clarividência do instinto. Enquanto os outros se atrapalham e se confundem de tanto pensar, Garrincha age com rapidez instintiva e incontrolável. [...] Diante dele, que não pensa, todos nós, que pensamos, somos uns lerdos, uns bovinos, uns hipopótamos. 
Embora faça-se uma diferença informal aqui entre o "pensar" e o "instinto", convém notar que este último envolve uma "clarividência" e que, portanto, embora não seja um refletir ou raciocinar, é também um certo tipo de pensar. Tampouco precisamos considerar aqui apenas atividades físicas para perceber como se mostra a diferença entre essas duas intrigantes formas de experiência: agora mesmo, ao ler este texto, o leitor absorto não precisa pensar em regras da gramática ou definições de dicionário para cada palavra, tal como faria se estivesse lendo o texto em uma língua que domina mal. Embora ao aprender uma nova língua possamos encontrar auxílio em estudar alguma carga de teoria linguística, dominar uma língua e dominar o conhecimento teórico a respeito de uma língua são duas coisas diferentes e só parcialmente conectadas. Até mesmo durante um processo de pensamento reflexivo, por exemplo, de um cientista entretido em ponderar um problema matemático, poderíamos talvez distinguir um elemento de experiência não teórico graças ao qual é possível ao cientista farejar suspeitas, seguir intuições, apreciar a "elegância" de um certo modo de desenvolver um argumento, e, por fim, de repente, ter uma ideia completamente inesperada e transformadora, uma ideia que certamente não é uma mera aplicação de qualquer pensamento anterior, mas algo novo que se constitui em meio a um processo no qual se está imerso e absorto. Tudo isso só é possível graças a um "instinto" que o cientista adquiriu após anos de treinamento e experiência. É só depois que tiver encontrado a nova ideia — sabe-se lá como! — que o cientista poderá tomá-la como objeto de reflexão, análise e escrutínio detalhado, e talvez mesmo como algo a ser "aplicado" em um nível mais estritamente técnico.

Com que frequência agimos preocupados em seguir instruções? Em cumprir um planejamento, executar um projeto? Aplicar uma teoria? Representar um papel ou praticar o que manda um discurso normativo previamente estabelecido e conhecido? Do ponto de vista da análise existencial, tudo isso corresponde a agir conforme uma orientação a partir do "ser simplesmente dado", isto é, de nossa capacidade de refletir e teorizar. Esse modo de agir antecipa o que vai acontecer e fornece parâmetros que devem se manter estáveis ao longo da ação, servindo-nos de suporte seguro para reagir ao que aparece. É um modo perfeitamente legítimo e natural de agir. A questão é: há também uma outra possibilidade de ação e orientação, dotada de sua própria riqueza? Acontece de nos esquecermos dela? Por quê? Esse esquecimento carrega também seus próprios perigos?

Quando a pedagogia fenomenológica suspeita que nossa maneira de lidar com o processo de ensino-aprendizagem em uma sala de aula possa estar sobrecarregada de uma valorização excessiva da teorização abstrata, há nisso uma imensidão de implicações em potencial. A primeira e mais simples implicação que podemos considerar é que acontece algum modo de proceder que bloqueia ou dificulta a imersão no interesse e a substitui pela transmissão de dados teóricos já determinados e acabados. Também há um problema quando o próprio processo de ensino-aprendizagem é entendido como um objeto já plenamente conhecido e dominado por uma teoria pedagógica a que cabe apenas executar. Assim, Langeveld, um dos expoentes da pedagogia fenomenológica, pensava que "o conhecimento pedagógico não visa controlar situações pedagógicas através de uma teoria racional. Este tipo 
de relação de controle entre teoria e prática, diz Langeveld, pertence ao domínio do tecnocrata" (apud van Manen, 1996, p. 43).

A perspectiva "tecnocrata" mencionada tem a ver com um tema complexo que a tradição fenomenológico-hermenêutica chama de "a questão da técnica". No momento, basta que a consideremos enquanto algo relativo a uma exacerbação da importância da teoria como um meio de controlar certas experiências para tentar garantir antecipadamente que tenham "sucesso", de acordo com critérios previamente estabelecidos. Reiteramos que há certas dimensões da vida e certas atividades nas quais algo assim pode ser perfeitamente legítimo e salutar. O problema que a pedagogia fenomenológica levanta é: até que ponto será esse o caso do processo pedagógico? Essa pergunta é quase chocante se considerarmos que hoje a educação, frequentemente encarada apenas enquanto um processo econômico, torna-se cada vez mais objeto de controle estatístico e de planejamento visando à eficiência de resultados. Porém, perguntamos: não haverá ao menos uma parte ou aspecto desse processo que não convém encarar sob essa perspectiva? Essas perguntas ecoam o entendimento de que o processo pedagógico é, em alguma medida, também uma experiência pré-teórica e, enquanto tal, requer um outro modo de consideração.

Essas perguntas nos abrem horizontes para além da tradição da pedagogia fenomenológica entendida no interior do período histórico estrito acima mencionado e em direção a um projeto mais amplo e aberto de uma pedagogia fenomenológico-hermenêutica. Em uma linha mais particularmente próxima à tradição da hermenêutica, por exemplo, encontramos a contribuição recente de Flickinger (2010, p. 6), que afirma:

A cada ideia de objetividade científica precede, necessariamente, um ato de construção do objeto a ser investigado, ou seja um ato "objetificador", baseado nas decisões prévias, negociadas entre os participantes responsáveis, os quais se veem obrigados a respeitar mutuamente as condições específicas de cada um. É impossível, neste ponto, abstrair das influências no diálogo, isto é, da habilidade de convencer, da confiabilidade dos parceiros ou da aceitabilidade ético-moral das posturas pessoais.

Flickinger (2010) chama a atenção para o fato de que o conhecimento teórico encontra um fundamento existencial na experiência do diálogo entre seres humanos. A exigência de impessoalidade na construção desse conhecimento diz respeito ao seu conteúdo, mas nunca pode dizer respeito ao processo pelo qual os métodos de pesquisa são definidos e o acesso ao conteúdo é construído. Isso não implica nenhuma suposição de que os resultados do conhecimento teórico são meros reflexos dos preconceitos previamente dados historicamente a um conjunto de subjetividades. De acordo com Gadamer (2005), cuja obra se baseia Flickinger (2010), toda compreensão da realidade é sempre pautada e limitada por preconceitos — no sentido de "pré-conceitos", isto é, ideias prévias nossas sobre o mundo, sobre as quais, por vezes, jamais refletimos ou que sequer percebemos que assumimos - e o projeto iluminista de conquistar um acesso puro e direto à realidade é incompatível com a estrutura histórica da experiência humana. Pois faz parte dessa estrutura ser 
sempre composta de uma parcela irrefletida. Não é possível tornar-se inteiramente autoconsciente, capaz de analisar exaustivamente todos os pressupostos e implicações de todas as próprias compreensões sobre o mundo. Contudo, para conhecer, tampouco é preciso livrar-se de todos os preconceitos. É preciso apenas aprender a reconhecer, analisar, criticar e transformar preconceitos a partir do diálogo com outras experiências, renovando esse processo continuamente ao longo do tempo. Esse é o sentido "histórico" da estrutura da experiência humana, entendida de modo fenomenológico-hermenêutico: estamos sempre inseridos em uma história que vai se desenrolando perante nossos olhos, limitados por preconceitos que vão sendo inesperadamente desafiados e confrontados pela realidade. Somos personagens dessa história, não narradores oniscientes - a pretensão ou a ilusão de ser onisciente é que são perigosas, pois, nesse caso, certos preconceitos se cristalizam e o movimento de transformação cessa. Assim, a existência de conhecimento depende de os seres humanos serem capazes de dialogar, com os outros e consigo mesmos, para pôr em movimento seus horizontes, e o desenvolvimento dessa capacidade é um problema epistemológico e pedagógico - e, como ressalta o autor, também um problema ético. Remetendo-se a Gadamer, Flickinger (2010, p. 93) entende esse diálogo como "disposição infinita de legitimar e fundamentar o dito". Legitimar e fundamentar significa responder a objeções, dar razões para sustentar posições e considerar a possibilidade de outras perspectivas. Trata-se de uma atividade que exige não apenas uso do intelecto, mas também uma “disposição", isto é, um conjunto de atitudes e habilidades emocionais. $\mathrm{O}$ adjetivo "infinita" aqui indica que a disposição a dialogar não deve ser encarada como mero meio para atingir certos resultados cognitivos, pois, nesse caso, ela poderia se encerrar ao obter tais resultados. Sendo infinita, a disposição para o diálogo precisa encarar o diálogo como um fim em si mesmo, uma atividade eminentemente nobre e humana da qual brotam criações e inovações em ritmo imprevisível. Para se manter constantemente aberto a essas transformações, é preciso cultivar o diálogo enquanto atividade incondicional. Nesse sentido, trata-se também de um imperativo ético, que coincide com o respeito e o cuidado com a condição humana.

Seguindo a linha dos raciocínios acima, torna-se evidente que a tarefa essencial do educador deve ser a de cultivar um ambiente aberto e estimulante ao diálogo. Pois está claro que "diálogo", aqui, não corresponde àquilo que nos acontece cotidianamente quando muitas pessoas emitem opiniões, cada qual sem ouvir nem ao outro nem a si mesmo. Ao contrário, fala-se para não ouvir, para convencer-se de que algo já é completamente sabido e não precisa de nenhum esforço de pensamento - e então todo tipo de preconceito gritantemente inadequado à realidade passa impune, e cada um começa até mesmo a pretender entortar a realidade para que caiba em seu ponto de vista. Um amontoado de pontos de vista estáticos e surdos digladiando-se na violência das "polêmicas" em que vence quem puder mais depressa deslegitimar e ridicularizar o outro - isso é algo menos próximo do diálogo do que o silêncio total e pode acontecer tanto em uma aula antiquada, na qual só o professor fala e todos devem se curvar a sua autoridade, como em uma aula moderna, em que todos falam de maneira aparentemente democrática e igualitária. Assim, enquanto professor de uma disciplina, cabe ao educador tentar estimular e 
conduzir o diálogo na direção de certo conjunto de temas e problemas, atento ao perigo de que o diálogo perca a força e se transforme na imposição de pontos de vista, ainda que sofisticados e qualificados. Pois bem: como fazer isso?

Van Manen, na esteira de Langeveld, propõe ao educador que conduz uma situação de aprendizagem: "a primeira pergunta pedagógica deve ser: como é, para a criança, experimentar uma situação como esta?” (van Manen, 1996, p. 48). Naturalmente, trata-se de uma pergunta que não pode chegar a resultados objetivos. Contudo, o propósito não é determinar o conteúdo dos estados mentais da criança ou qualquer coisa do gênero. É, simplesmente, engajar-se em um diálogo: ficar atento e procurar ler as mensagens que o educando emite e que sinalizam algo a respeito de sua postura, disposição e ponto de vista. Isso inclui linguagem corporal, tom de voz, falas cotidianas, gestos etc. A isso devem-se somar a leitura do espaço, por exemplo, do local em que a escola se encontra; a consideração das informações do setor de acompanhamento pedagógico a respeito do educando, quando disponíveis; os relatos do educando a respeito de seu próprio cotidiano e suas dificuldades, etc. $\mathrm{O}$ olhar necessário a essa leitura deve ser mais concentrado e extenuante do que aquele que permeia as mesmas leituras em situações não pedagógicas, e a reação às mensagens que ele detecta precisa ser também mais contida, ponderada e comedida, a fim de evitar emitir respostas apressadas e inadequadas. É preciso também alguma reflexão e imaginação, assim como a cautela em considerar que o quadro que se forma a respeito de uma situação ou estudante é sempre incompleto e se baseia, por vezes, em algumas suposições que se precisa permanecer aberto a reconsiderar eventualmente. Tudo isso se torna ainda mais difícil para o professor que leciona para várias turmas, cada uma com dezenas de alunos, por apenas um par ou dois de horas por semana e com um cronograma apertado de objetivos a atingir. No entanto, a pergunta permanece diretriz: quem são esses estudantes? Como é o seu mundo? Por que estão aqui? Por que apresentam esse ou aquele comportamento? Que interesse podem ter em estar aqui? Em resumo: como será, para eles, experimentar uma situação como esta? Essa pergunta coloca logo para o educador uma outra, que evidencia a natureza bilateral desse diálogo: o que eu mesmo estou fazendo aqui com meus estudantes? O que tenho a ensinar? Em suma, qual o sentido de estar aqui com eles? Frequentemente não temos tempo para esse tipo de pergunta e subestimamos sua importância, mas, independentemente disso, ou talvez por isso mesmo, essa pregunta, por vezes, nos atinge e atravessa como um raio, desorientando, angustiando e exaurindo emocionalmente. É preciso não sufocá-la, não menosprezá-la como uma inconveniência, não defender-se dela com excesso de "profissionalismo" e atitude burocrática, mas ouvi-la, especialmente quando não se souber respondê-la.

O diálogo entre professores e alunos, educadores e educandos, floresce à medida que se consiga cultivar uma atmosfera pedagógica. É o que propõe Bollnow (1989), ao definir essa atmosfera como: "todas as condições emocionais fundamentais e qualidades humanas conscientes que existem entre educador e criança e formam a base para cada relacionamento pedagógico"(Bollnow, 1989, p. 6). Trata-se, portanto, da atmosfera que experimentamos enquanto estamos imersos em um certo relacionamento, e não de um conjunto de emoções analisado por um psicólogo que, 
enquanto tal, precisa encontrar-se em um ponto de vista minimamente exterior ao fenômeno observado, que então poderá analisar em termos de categorias conceituais e relações causais. É por isso que o educador treinado em psicologia, embora disponha de alguns recursos a mais para refletir sobre sua prática, não se encontra em situação fundamentalmente diferente do educador sem o mesmo treinamento formal no tocante ao desafio de orientar-se em meio à imersão na relação pedagógica, a qual sempre requer o elemento que chamamos anteriormente de "instinto" e que se desenvolve por treinamento específico e experiência na prática de ensino. Pois o psicólogo nunca pode analisar-se a si mesmo em tempo real e ser plenamente consciente de si e das situações em que está inserido, para tê-las sob controle a partir do horizonte de sua especialidade científica. Assim, a definição de Bollnow (1989) situa a atmosfera pedagógica em um nível fenomenológico, infenso a qualquer psicologismo reducionista, e que retoma sob outro aspecto o caráter histórico da experiência humana, tal como mencionamos.

Cabe-nos então perguntar mais a fundo, por nossa própria conta: o que é a atmosfera pedagógica? É uma afetividade que une educadores e educandos em torno do processo de aprendizagem. É sentir-se unido a companheiros de aventura, com os quais se partilha descobertas e interesses e se vive histórias relevantes e memoráveis. Todo adolescente egresso da escola lembrará disso muito mais do que de qualquer conteúdo técnico. Contudo, a atmosfera pedagógica e os laços que ela proporciona dependem de acontecer um aprender. É ele que irmana e vincula quem dele partilha. Pois, no aprender, um sentido aparece de repente e algo "brilhante" acontece; esse brilho continua iluminando outras experiências ao longo do tempo e se torna referência memorável. A criança e o adolescente costumam demonstrar disponibilidade excepcional para esse acontecimento, e mesmo de más circunstâncias de aprendizagem podem tirar suas próprias lições e encontrar sentido para suas próprias histórias. O bom educador tenta mostrar a dinâmica de sentido daquilo que procura ensinar, a fim de que o educando dela se aproprie à sua própria maneira, estimulando essa força criativa de apropriação. Por outro lado, a atmosfera pedagógica, enquanto preparação e cultivo, envolve enfrentar certa resistência e dispersão, que derivam do fato de o elemento vinculante ainda não ter se mostrado ou se renovado. Por isso, é preciso reconhecer que a dificuldade em imergir na atmosfera tem sua legitimidade e que o educador não tem o poder de instaurá-la a seu bel-prazer, mas pode apenas cultivá-la e esperar por ela. Reconhecer isso é fundamental para superar um obstáculo a mais: a culpa e o desânimo resultantes de uma ambição desmedida, ainda que por objetivos extremamente bem-intencionados ou altruístas.

Nosso caminho até aqui permite ter uma ideia das implicações da distinção heideggeriana entre "ser simplesmente dado" e "manualidade" para uma pedagogia fenomenológico-hermenêutica. Vimos que ela implica a necessidade de cuidado para evitar subordinação da experiência vivida à teorização, cuja consequência seria uma abordagem tecnocrata do processo de ensino-aprendizagem. Essa abordagem se expressaria sob a forma de negligência para com o caráter dialógico e histórico da experiência humana, que corresponde concretamente à incapacidade de ler, interpretar e responder ao contexto em que aquele processo ocorre. Essa leitura não ocorre porque não se colocam perguntas que dirijam o olhar para o interior 
da própria experiência em que se está imerso, por contraste ao tipo de pergunta científica em que nos colocamos para fora da situação analisada e procuramos antecipá-la e estabelecer certos parâmetros de controle e sucesso. A consequência é que o processo de ensino-aprendizagem se torna mecânico e vazio de sentido, e a atmosfera pedagógica se esvai, substituída pela ansiedade por obter resultados e terminar depressa um processo penoso cuja utilidade só se justificará quando ele acabar. É possível que, mesmo assim, estatísticas bem-sucedidas de resultados em determinados exames sejam obtidas, e, no entanto, é lícito perguntar se algo relevante não se perdeu. Ou perguntar, ainda, se não haverá crescimento da insalubridade emocional dos ambientes escolares modernos que independe do quão eficiente seja a escola e que talvez tenha a ver com a demanda de que escolas sejam, acima de tudo e a todo custo, eficientes - pois, então, quando se fracassa, nada terá tido valor; e, quando se tem sucesso, é ao custo de ter suportado um processo de excruciante adiamento do sentido e aprendido que submeter-se de novo e de novo a processos assim é o único caminho na vida. Como suportar um caminho assim, a não ser anestesiado por doses exageradas de entretenimento e consumo? E como suportar, então, caso se esteja privado da possibilidade de acesso a entretenimento e consumo?

O horizonte dos problemas e das reflexões que a tradição da pedagogia fenomenológico-hermenêutica nos abre exige, portanto, colocar a pergunta: como orientar a execução do processo de ensino-aprendizagem? Todavia, a formulação dessa questão dessa maneira, por si só, já soa problemática, pois supõe que esse processo é alguma coisa a ser produzida por um sujeito exterior a ele, que é capaz de antecipá-lo inteiramente e então apenas executar o que antecipou. O professor, usualmente, seria o sujeito do processo de ensino-aprendizagem, aquele que o controla unilateralmente, ainda que eventualmente procure ajustá-lo a seus alunos, que de todo modo são objetos do processo, isto é, são aqueles que a ele resistem e que devem ser modificados por ele. Toda essa estrutura se torna estranha e questionável a partir da pedagogia fenomenológico-hermenêutica. É preciso novamente perguntar: o que é, em si, o processo de ensino-aprendizagem? Já podemos rascunhar uma resposta: trata-se de uma dinâmica de experiências e acontecimentos da qual todos partilham e que ninguém produz ou controla, mas que é possível cultivar como possibilidade. Nesse caso, então, nossa questão reformulada seria: como orientar-se em meio a esse processo, cultivando-o e contribuindo para que possa acontecer em seu pleno vigor? A pergunta reformulada supõe que esse processo tem certa autonomia e que cabe a seus participantes acompanhá-lo. O que significa isso?

\section{COMO ORIENTAR-SE EM MEIO AO PROCESSO DE ENSINO-APRENDIZAGEM?}

Antes de mais nada, esclareçamos que nossa pergunta-título aqui não implica de modo algum que professores e educadores devam abrir mão de todo tipo de estudo teórico, planejamento ou treinamento prévio para lançar-se irrefletidamente a seu trabalho, confiantes em algum tipo de espontaneidade mágica capaz de tudo solucionar. Supor que a pergunta leve a essa implicação pressupõe que, ou bem uma 
ação é mera execução de planejamentos e se deixa pautar inteiramente por eles, ou bem é completamente cega, impulsiva ou aleatória. Essa premissa perde de vista completamente o problema fenomenológico do modo de existência caracterizado como "manualidade", experiência pré-reflexiva ou pré-teórica, tal como expusemos. Não obstante, mesmo que tenhamos vislumbrado esse modo de experiência como algo distinto e próprio, ainda há muito que pensar a respeito dele. Pois não apenas ele deve ter seu próprio modo de orientação, como também deve relacionar-se de alguma maneira com a teorização, que não fica excluída enquanto modo relevante de experiência.

A pergunta por um modo de orientação em meio a um processo que não se deixa reduzir inteiramente a teorizações prévias tem raízes tão antigas quanto a própria noção de teoria. A discussão a respeito da phronesis, a prudência, no pensamento de Aristóteles, tem algo a ver com isso. Gadamer (2005, p. 44-83) observa que a história das ciências do espírito - mais ou menos as que hoje chamamos de "ciências humanas" - passa por lidar com essa mesma questão, sob o ponto de vista do desenvolvimento cognitivo humano. Os conceitos de formação, senso comum, juízo e gosto aí se entrelaçam enquanto tentativas de apontar para um modo de orientação no mundo capaz de criar e transformar conceitos, e não apenas seguir aqueles que se acham disponíveis. Apesar de suas importantes nuances e variações, podemos resumir esses conceitos da seguinte maneira. Formação, bildung, é um conceito referente à educação e indica o cultivo de uma sensibilidade para as novas possibilidades de teorizar desencadeadas por cada experiência. Senso comum ou bom-senso (sensus communis, bon sens) seria uma capacidade de adaptar-se à especificidade de cada situação prática, especialmente no tocante ao convívio com os outros, de modo a perceber que certas regras gerais normalmente seguidas já não se aplicam ou não valem inteiramente em certos casos. O juízo, ao contrário, seria a capacidade de aplicar regras e submeter casos particulares a princípios universais, sendo inútil compreendê-los teoricamente sem saber aplicá-los. Por fim, o gosto, a princípio referente ao elemento mais idiossincrático da orientação humana, avesso a qualquer racionalidade, mostra-se como um sentido que se pode cultivar em direção ao bom gosto, isto é, o gosto culto, que equilibra a própria individualidade e os padrões da cultura ou mesmo da moda, produzindo um estilo próprio e refinado nas escolhas e avaliações a respeito dos objetos do gosto. Nesses quatro conceitos, é interessante observar que se trata sempre de tentar pensar uma interseção entre sensibilidade e racionalidade e uma certa dialética entre processos indutivos e dedutivos. Produzir conceitos, tentar aplicá-los, ajustá-los a cada caso ou ajustar cada caso a eles, verificar as inadequações daí resultantes, identificar individualidades idiossincráticas e novamente tomá-las como oportunidade de inventar novas universalidades. Operar um constante ajuste entre particular e universal, sensível e inteligível, em que os polos dessas dicotomias se transformam dialeticamente. Em tudo isso há fluidez e criatividade. Trata-se da fluidez e da criatividade do teorizar, que, enquanto atividade viva, nunca é mera aplicação mecânica de conceitos dados. Considerados a partir da formação (Bildung), os quatro conceitos apontam para um sentido de educação enquanto desenvolvimento da capacidade teórica e para o papel do educador, não enquanto transmissor de conteúdos, mas enquanto conhecedor e 
cultivador desse desenvolvimento. Não obstante, mesmo tomando o teorizar nesse sentido mais amplo e fundamental, ainda assim cabe perguntar se o processo de ensino-aprendizagem está nele contido ou se o excede e exige a consideração de outra dimensão de experiência. $\mathrm{O}$ aspecto mais interessante desses conceitos é que eles apontam precisamente para a fronteira da atividade de teorizar, uma região de onde essa atividade extrai sua criatividade e encontra seus limites.

Experimentemos tomá-los sob outra ótica, focalizando-os a partir do conceito de bom-senso. Essa mesma palavra ressoa em nosso uso comum aproximadamente no mesmo sentido quando se trata da prática de um educador. Bons professores, sabemos, são aqueles que têm bom-senso. $\mathrm{O}$ que isso significa, geralmente? Trata-se de um estar aberto à situação. Não é o mesmo que um processo de diagnose formal, a chamada avaliação diagnóstica, da qual se extraem dados para ajustar o plano de curso em continuidade com o nível acadêmico da turma. Professores com bom-senso são aqueles que estão atentos para todo sinal de que uma situação exige sair do papel estrito de profissional e estabelecer um diálogo entre seres humanos. O decisivo, então, é a sinceridade, a transparência na discussão a respeito do que é que se está fazendo em conjunto e que adaptações são razoáveis e aceitáveis. Por exemplo: dá-se uma vista de prova. Um aluno reivindica a revisão da correção de uma questão. $\mathrm{O}$ bom-senso exige que o professor esteja disponível para explicar e justificar os critérios de correção que utiliza, que procure mostrar o sentido pedagógico da avaliação para além de mera formalidade burocrática. Que esteja aberto para ouvir objeções e questionamentos, não apenas sobre a exatidão da aplicação dos critérios de correção, mas quanto ao verdadeiro sentido de ter de fazer uma prova, e em especial aquela. O que torna a aplicação de provas e notas frequentemente um evento tenso é que todos estão pré-condicionados a assumir uma série de premissas inadequadas; por exemplo, de que a nota reflete o valor intrínseco do aluno enquanto ser humano, ou de que, ao contrário, a prova nada mede de fato nem tem utilidade alguma, mas é apenas um estorvo do qual é preciso se livrar depressa. As raízes profundas de premissas como essas são em si um tema a se pensar. Todavia, o bom-senso na situação em questão reside em não perder de vista que o objetivo da avaliação é contribuir de algum modo para fazer aprender, e que é razoável discutir até que ponto ela serve bem a esse propósito ou que especificidades da experiência do aluno podem exigir adaptações para ajudá-lo a aprender melhor por meio dela. $\mathrm{O}$ que frequentemente afasta o professor de compreender algo aparentemente tão óbvio? Pode ser, por exemplo, o fato de que alguns alunos aferram-se a alguma daquelas premissas inadequadas e, por isso, procuram, de má-fé, exercer algum tipo de manipulação ou pressão injusta sobre o professor para extrair dele vantagem. Essa atitude ofende, e ter de encará-la repetidas vezes e sob a influência de outros fatores pode levar o professor a se ressentir. Ressentido, ele tenderá a fechar-se perante todo aluno como se estivesse diante de uma ameaça em potencial, um mau-caráter em potencial que apenas aguarda uma oportunidade. Para defender-se, encontrará refúgio em aplicar regras de forma draconiana, fundamentando-as meramente em sua autoridade e recusando-se a discuti-las ou esclarecê-las, e isso tenderá a levá-lo a cometer erros e a procurar sempre encobri-los, inviabilizando qualquer relação de confiança e transparência com os alunos com os quais convive. De fato, movidos 
por esse exemplo, é provável que os alunos adquiram uma tendência a serem mais desonestos e hostis do que se sentiriam tentados a ser normalmente, o que parecerá ao professor confirmar suas suspeitas e produzirá um círculo vicioso. Por fim, será difícil convencer uma turma nessas condições a levar os estudos a sério, ou aquele professor de que seria mais razoável ser mais flexível, compreensivo e vulnerável, mesmo com uma turma que se lhe tornou hostil. O bom-senso é uma abertura para a situação, que, no caso do processo de ensino-aprendizagem, é um convívio entre seres humanos unidos pelo interesse em aprender. Ele se perde quando o sentido da situação é obstruído e seus participantes são levados a se fechar, refugiando-se no mero cumprimento de regras e papéis burocráticos e no correspondente impulso a violar esses papéis sem sentido ou explorá-los a favor de interesses impertinentes. Sendo abertura para a situação, o bom-senso é um desprendimento das antecipações teóricas que não as descarta, mas fundamenta-as e ajusta-as a partir de uma sensibilidade para o sentido. A formação da capacidade cognitiva, do juízo prático de aplicabilidade e do refinamento do gosto são possibilidades que se desenvolverão diferentemente conforme haja ou não bom-senso. Pois alguém pode ser inteligente, eficiente e refinado, mas não ter bom-senso.

O que procuramos esboçar por intermédio do exemplo acima é um problema cuja envergadura cresce conforme levamos em conta a complexidade de tudo que pode obstruir o sentido das situações em que nos encontramos e quão desafiadora à nossa compreensão é a simplicidade da premissa de que o sentido do processo pedagógico é a experiência fenomenologicamente distinta de aprender. Tentarei apontar na direção desse problema novamente, mas por outro caminho, a partir de um relato de minha própria experiência profissional. Entre os anos de 2015 e 2018, mantive no Colégio Pedro II do Engenho Novo um grupo de estudos com alunos de diferentes séries do ensino médio. Muitas vezes, aqueles que se formavam continuavam a frequentar o grupo no ano seguinte, como ex-alunos visitantes. Acontecia semanalmente por uma ou duas horas em horário extraclasse. A frequência era caótica: havia dias com 10 alunos, outros com um ou dois. Os participantes iam e vinham como queriam ou podiam, e cabia a mim manter a estabilidade da oferta do espaço e do tempo para o grupo. Começamos com o objetivo de aprofundar certos pontos do currículo regular de filosofia, que víamos em sala de aula, mas em pouco tempo a dinâmica desse grupo de estudos tornou-se totalmente diferente de uma aula. Os alunos traziam interesses os mais variados para discutir: notícias de jornal que leram, videogames que jogavam, quadrinhos, episódios de seu cotidiano. Eu procurava ouvi-los e encontrar o elemento filosófico em cada interesse que permitisse discuti-lo. Trazia, então, textos que líamos juntos ou filmes para assistirmos e debatermos. Era impossível planejar muita coisa com antecedência e, do ponto de vista acadêmico, não havia um objetivo temático muito definido ou uma continuidade muito duradoura de conteúdos. Eu procurava propor algumas discussões, mas também criar um ambiente aberto para as inquietações deles e responder a elas conforme apareciam. Depois de bastante tempo imerso nesse trabalho sem ter plena consciência do que estava acontecendo, dei-me conta de que o aparente caos daquele grupo de estudos, ao qual, no entanto, ninguém tinha nenhuma obrigação de sequer comparecer, era o invólucro de um simples e puro entusiasmo de estudar e 
pensar em conjunto. Não como um meio para obter resultados em provas ou realizar projetos acadêmicos, nem mesmo como um meio para obter resultados cognitivos específicos. Cada participante tirou proveito da atividade do seu próprio jeito e de maneiras que eu mesmo não poderia mensurar ou controlar, mas que pude verificar de modo geral a partir das manifestações continuadas de interesse na atividade em si. Ela era o principal e quase único objetivo.

Será que na simplicidade de uma atividade como a deste relato não se oculta uma obviedade que, contudo, nos tornamos, por vezes, sofisticados e atarefados demais para compreender? Em que medida, como educadores, damos algum espaço em nossas práticas para o simples objetivo de encontrar alegria em estudarmos com nossos estudantes? Aliás - quando é que nós mesmos, que fazemos do estudo uma profissão e que escolhemos fazê-lo em algum momento por gostar de estudar, conseguimos obter o tempo e as condições para simplesmente estudar o que nos fascina e comove, em vez de "trabalhar" com o conhecimento, e de tal maneira que parece, às vezes, que perdemos o gosto por aquilo que outrora considerávamos nossa vocação? Isso não implica abrir mão dos objetivos pedagógicos e curriculares de praxe. O que está em questão é a possibilidade de experimentar o conhecimento, não como um meio, mas como um fim em si mesmo - um sentido em si mesmo.

Retomando, então, nossa pergunta-título: como contribuir para criar um ambiente no qual, mais do que qualquer "desenvolvimento" acadêmico ou intelectual em particular, esteja em jogo abrir a possibilidade de um sentido? Como ir ao encontro do aprender como um sentido para a existência humana? Procuraremos desenvolver essas perguntas por meio de um diálogo livre com o pensamento de Paulo Freire 4 .

Certa vez, Paulo Freire proferiu um discurso sobre "a importância do ato de ler", em que descrevia seu próprio processo de alfabetização quando criança. Em suas palavras, essa tentativa de descrição "é como se eu estivesse fazendo a 'arqueologia' de minha compreensão do complexo ato de ler, ao longo de minha experiência existencial" (Freire, 1989, p. 12). A certa altura, ele afirma:

A decifração da palavra fluía naturalmente da 'leitura' do mundo particular. Não era algo que se estivesse dando superpostamente a ele. Fui alfabetizado no chão do quintal de minha casa, à sombra das mangueiras, com palavras do meu mundo e não do mundo maior dos meus pais. (Freire, 1989, p. 11)

Aprender a ler não é, aqui, adquirir conceitos. É adquirir linguagem. A criança que aprende a ler e escrever primeiro aprendeu espontaneamente a falar e ouvir. Porém, no falar e ouvir já se encontra um ler os sinais do mundo. Nesse sentido, aprender as letras é, novamente, aprender a ler o mundo, pois o ler e escrever as letras torna-se um universo. Antes de poderem se referir a abstrações e elaborações refletidas, as palavras são aprendidas como a transparência das próprias coisas-sinais, tal como se mostram na experiência. Será que no aprender a ler encontra-se, de

4 Em um estudo mais geral e sistemático, as influências da tradição fenomenológica no pensamento de Freire encontram-se bem documentadas em Giovedi (2006). 
modo exemplar, a essência de todo aprender? Será todo aprender sempre algum tipo de aprender a ler?

Em Pedagogia da autonomia, Paulo Freire (1996) acrescenta, a respeito da experiência cotidiana de sala de aula:

Mas devo estar atento à leitura que fazem de minha atividade com eles. Precisamos aprender a compreender a significação de um silêncio, ou de um sorriso ou de uma retirada da sala. $\mathrm{O}$ tom menos cortês com que foi feita uma pergunta. Afinal, o espaço pedagógico é um texto para ser constantemente "lido", interpretado, "escrito" e "reescrito". Neste sentido, quanto mais solidariedade exista entre educador e educandos no "trato" deste espaço, tanto mais possibilidades de aprendizagem democrática se abrem na escola. (Freire, 1996, p. 97)

Aqui, a convivência entre educador e educandos é definida como uma leitura em conjunto. Aquilo que é lido em conjunto - e reescrito em conjunto - , o texto, é o "espaço pedagógico". O que significa interpretar um espaço como um texto compartilhado? Por que o decisivo para abrir as possibilidades desse espaço é uma "solidariedade" entre os que se ocupam do "trato" com ele? Não se trata do espaço geométrico estudado pela física e pela matemática. É um espaço feito de sinais. Agir, mover-se no espaço, é, ao mesmo tempo, interpretar sinais e sinalizar. $\mathrm{O}$ silêncio, o sorriso, a retirada, o tom de voz, são sinais de uma interpretação de mundo, de um modo de ler os sinais em meio aos quais se existe. Queiram ou não, saibam disso ou não, professores e alunos dialogam e trocam mensagens incessantemente. Uma aula nunca é, de fato, dada "para as paredes". Ela pode, no máximo, ser dada com o acréscimo da mensagem que diz que o modo como ela será recebida por seres humanos pouco importa, pois não se trata ali de um diálogo, mas apenas da execução de um plano de aula.

Aprender a ler se desenvolve como um aprender a reler. O que, no começo, é o desafio da alfabetização permanece, depois, como o desafio do desenvolvimento daquilo que Freire (1996) chama de "leitura crítica". Ele diz: "A compreensão do texto a ser alcançada por sua leitura crítica implica a percepção das relações entre o texto e o contexto" (Freire, 1996, p. 9). O texto já sabemos ler, porque fomos alfabetizados. O contexto também já sabemos ler, porque vivemos nele. No entanto, a leitura crítica é aquela que aprende a perceber as relações entre texto e contexto. Decisivas, aqui, são as palavras: "perceber" " "relações". Pois as relações estão em um movimento em que é preciso manter-se atento para perceber, para deixar aparecer. Esse movimento é o estranhamento provocado pelo encontro entre textos que se contradizem, que falam cada qual uma língua diferente, em um tom diferente. Leitura crítica é olhar em busca das relações que costuram textos e contextos: de onde falam, para onde, com quem. A costura que amarra tudo isso é a realidade - essa estranha realidade, feita de tantas realidades diferentes, contraditórias e mutáveis.

Aqui também procurarei recorrer a um relato de experiência que ajude a tornar concreto o que parece demasiado abstrato. Fiz um exercício com algumas turmas de educação de jovens e adultos (EJA) no qual projetei para elas slides com palavras, frases e imagens que admitiam múltiplas interpretações, e pedi a cada turma que 
me dissesse o que estava ali escrito ou o que elas estavam vendo. Um dos slides, por exemplo, continha simplesmente a palavra fogão, que alguns entenderam se referir ao aumentativo de "fogo", outros, a um eletrodoméstico e outros, ao time de futebol do Botafogo. Eu provocava a turma a falar e a investigar não apenas que sentidos diferentes se poderia ler nos textos, mas também por que eram possíveis diferentes sentidos e como fazer para descobrir qual poderia ser o mais adequado. Algumas frases apresentavam ambiguidade lexical, outras, gramatical, e outras, ainda, podiam ser lidas como metáforas ou apresentar algum uso pragmático com sentido diferente do significado literal da frase. Uma das frases mais discutidas foi: "a porta está aberta”. Além do significado literal, ela poderia significar um convite para sair da sala (especialmente se fosse dita em tom raivoso), ou indicar, ao contrário, que uma boa oportunidade a respeito de algo estaria disponível, ou um pedido para que se fechasse a porta, e assim por diante. O exercício permitiu desfazer uma premissa que os alunos carregavam consigo: que um texto é um recipiente que guarda um conteúdo unívoco e autoevidente, mas que eles tinham dificuldade em acessar porque lhes faltava alguma capacidade cognitiva. Essa premissa se desfez pela experiência de que o mesmo texto poderia ter diversos significados, que o sentido de um texto se efetiva na relação com um contexto que é preciso imaginar e investigar, e que a leitura é um processo ativo de pensamento e descoberta. A partir desse trabalho, pudemos prosseguir depois para uma discussão sobre como identificar notícias falsas e seus mecanismos de induzir a certas interpretações apressadas e equivocadas de certos textos e imagens, levando-se em conta que nem toda notícia falsa é simplesmente mentirosa, mas lança mão, por vezes, de ambiguidades e mecanismos retóricos e apresenta, como todo texto, uma intencionalidade, um recorte de informações e relações guiado por interesses. Pode-se dizer que trabalhamos epistemologia. Porém, não lemos nenhum texto teórico sobre epistemologia. Acessamos esse conteúdo refletindo em conjunto sobre nossos próprios processos cognitivos em situações cotidianas, fixando e organizando algumas observações conceitualmente, mas limitando o arcabouço teórico àquilo que remetesse o olhar de volta à nossa atividade. No semestre seguinte, estudamos ética por meio da discussão de dilemas morais fictícios, envoltos em narrativas detalhadas, que admitiam diferentes soluções, e os alunos se ocuparam em discutir e justificar as soluções que consideravam mais justas. $\mathrm{O}$ objetivo não era, de fato, solucionar os dilemas, mas exercitar o olhar para a multiplicidade de perspectivas e a necessidade de fundamentação em um assunto que facilmente suscita fechar-se em uma convicção habitual e genérica. Mais uma vez, o detalhamento dos contextos dos dilemas foi o elemento que provocou a perceber o caráter demasiado abstrato e descontextualizado de algumas respostas iniciais aparentemente óbvias. Dei um curso parecido algumas vezes no ensino médio regular, mas com uma carga teórica maior, comparando as bases das éticas de Kant e Aristóteles. Nesse mesmo semestre, estudamos na EJA filosofia política por meio de um exercício em que os alunos, em grupos, precisavam se imaginar perdidos em uma ilha deserta depois de um naufrágio, na companhia de algumas dezenas de desconhecidos, e eram desafiados a encontrar um modo de organização coletiva que permitisse sobreviver em um ambiente selvagem. O exercício pedia resposta a uma série de perguntas específicas a respeito de como seria o processo de tomada de decisões, a divisão de tarefas, a divisão de alimentos ou outros produtos 
do trabalho, a reação a infrações às regras, de que maneira avaliar com justiça se alguém acusado de uma infração fosse realmente culpado, e assim por diante. Por fim, comparamos e discutimos as respostas de cada grupo. Então, trouxe à turma alguns trechos da declaração universal dos direitos humanos e mostrei-lhes que eles haviam chegado mais ou menos às mesmas teses que os principais artigos desse documento assumiam como bases para constituir uma comunidade política - e notei, pela surpresa em alguns rostos, que a expressão "direitos humanos", para eles, tinha até então um significado negativo, e que teriam se predisposto a se fechar ao tema se tivéssemos começado por ler a declaração, em vez de chegar a ela no fim. Foi um curso de filosofia política que poderia ter envolvido a leitura de textos clássicos do contratualismo, mas que, mesmo sem recorrer a isso, abordou os problemas desses textos por meio do diálogo com a realidade social dos alunos segundo seus próprios relatos. Foi, conforme eu já imaginara, a dinâmica na qual surgiram mais tensões entre as posições diferentes de cada aluno. Por isso, foi a última atividade do ano, realizada quando todos já haviam estabelecido tanto quanto possível um vínculo de convívio e camaradagem. Da minha parte, enquanto professor, foi fundamental abrir mão de qualquer pretensão de convencer os alunos de qualquer posição minha - o que não significa que considerasse indevido eventualmente expressar uma posição —, mas não abrir mão, em nenhum momento, de tentar convencê-los a conviver respeitosamente e dar-lhes o exemplo quanto a isso, pois essa é uma premissa sem a qual não haveria sentido em nos reunirmos naquela sala de aula. Nós, acadêmicos, tendemos ao vício de nos preocuparmos demais com um determinado discurso que alguém defenda em um determinado momento e a querer vencer no âmbito do discurso e ter razão, acreditando que todos os males do mundo se corrigem quando as pessoas começam a dizer as mesmas coisas e repetir as mesmas terminologias, frases de efeito ou palavras de ordem. No entanto, as posições de alguém no nível do discurso não correspondem necessariamente a suas ações, nem costumam mudar quando alguma outra pessoa pretende impor-lhe suas razões. Essas posições mudam, em seu próprio ritmo natural, quando ocorre, na prática, um diálogo - pois dialogar é uma prática. Se há algum convencimento pertinente ao papel de professor, creio não se tratar de um convencimento a favor de um determinado discurso, mas a favor da prática do diálogo, sem a qual a exposição de diferentes discursos não tem realmente sentido. Não é um convencimento quanto a um lugar predeterminado a que se deva chegar ao conversar, mas simplesmente quanto a valer a pena conversar. Esse convencimento também não encontra sua eficácia em uma mera fala, mas em um exemplo prático constante que, sem dúvida, exige concentração e cuidado, é emocionalmente desgastante e pode eventualmente fracassar.

Como orientar-se em meio ao processo de ensino-aprendizagem? De acordo com todo o nosso percurso, essa pergunta aponta para um orientar-se pré-teórico que, todavia, inclui e incorpora em si também o teorizar. Esse orientar-se envolve atenção constante para o perigo de deixar-se levar por uma perspectiva tecnocrata, que privilegia sentidos já constituídos em detrimento do esforço de acompanhar a gênese do sentido, isto é, exercitar a prática do diálogo com os outros e consigo mesmo, enquanto um aprender a ler o mundo sempre renovado. Concentrar-se nesse exercício é cultivar uma atmosfera pedagógica e, a partir dela, o bom-senso para responder ao imprevisto de cada situação pedagógica. 


\section{CONCLUSÃO}

Neste ensaio, procuramos construir o caminho de um olhar capaz de ver a prática pedagógica como um fenômeno distinto, em vez de um objeto teórico. Procuramos tornar sensível a questão a respeito de como acessar esse fenômeno e orientar-se em meio a ele enquanto participante dele, superando as obstruções provenientes de premissas e abordagens inadequadas que assumimos imperceptivelmente. Tudo isso se fundamenta na dimensão fenomenológico-hermenêutica do aprender enquanto esforço de viver e pensar o sentido existencial que permeia as práticas pedagógicas. Essa dimensão do aprender não exclui outras dimensões mais cotidianamente conhecidas, como memorizar um conteúdo ou treinar um procedimento padronizado de execução de uma tarefa. Ao contrário, trata-se da vitalidade de todo aprender, que impede que seus aspectos cotidianos se transformem em mera burocracia e se desenvolvam em uma atmosfera opressiva correspondente à execução de uma obrigação sem sentido.

Em ensaio intitulado "Aprender e ensinar", o prof. Carneiro Leão (1977) acena na direção que procuramos seguir, quando afirma: "Aprender a conhecer o sentido constitui a base de sustentação e o fundamento de possibilidade para qualquer outro aprender" (Leão, 1977, p. 47). Nosso percurso procurou criar uma via de acesso àquilo que essa afirmação sintetiza, construindo problemas prévios à sua consideração, apontando desdobramentos e procurando fornecer exemplos concretos. Em nosso entender, essa discussão é o ponto mais importante do projeto da pedagogia fenomenológico-hermenêutica, e procuramos contribuir para esse projeto aprofundando essa discussão e destacando sua centralidade.

Não obstante, mostrou-se que o sentido fenomenológico do aprender deve, em sua acepção mais própria, permanecer sempre um problema do qual cada educador e cada educando se aproprie à sua própria maneira e conforme sua própria experiência. Como uma imagem sintética desta conclusão, podemos evocar a figura de Sócrates. Em ensaio intitulado "Filosofia e política", Hannah Arendt (1990, p. 81) afirma sobre Sócrates:

O que Platão chamava de dialegesthai [diálogo, dialética], Sócrates chamava de maiêutica, a arte do parto: ele queria ajudar os outros a dar à luz o que de todo modo pensavam, a encontrar a verdade da doxa [opinião] que possuíam. [...] O papel do filósofo, então, não é governar a cidade, mas ser seu "incômodo"; não é proclamar verdades filosóficas, mas tornar os cidadãos mais verdadeiros.

De acordo com esse ponto de vista, a figura do filósofo tornou-se, ao longo do tempo e com impulso decisivo de Platão, aquela de alguém que chega a verdades absolutas, mas, para Sócrates, tratava-se de alguém continuamente empenhado em dar à luz diferentes perspectivas sobre o mundo por meio do diálogo. Pois o sentido alheio, emprestado de uma experiência de outrora, caduca e cobra sua dívida que, negligenciada, adquire proporções que recobrem e nublam a totalidade da existência. Esta se renova e revigora quando, ao aprender qualquer coisa, acontece 
simultaneamente uma maiêutica, um parto do sentido a partir do qual o aprender se ilumina desde o próprio existir enquanto ser humano.

\section{REFERÊNCIAS}

ARENDT, H. Philosophy and Politics. Social Research, v. 57, n. 1, p. 73-103, 1990. BOLLNOW, O. F. The pedagogical atmosphere. Phenomenology and Pedagogy, v. 7, p. 5-11, 1989. https://doi.org/10.29173/pandp15111

CERBONE, D. Fenomenologia. Petrópolis: Vozes, 2014.

FLICKINGER, H.A caminho de uma pedagogia hermenêutica. Campinas: Autores Associados, 2010.

FREIRE, P.A importância do ato de ler: em três artigos que se completam. São Paulo: Autores Associados; Cortez, 1989.

FREIRE, P. Pedagogia da autonomia: saberes necessários à prática educativa. São Paulo: Paz e Terra, 1996.

GADAMER,H.Verdade e método. 7. ed. Petrópolis: Vozes; Bragança Paulista: Editora Universitária São Francisco, 2005.

GIOVEDI, V.A inspiração fenomenológica na concepção de ensino-aprendizagem de Paulo Freire. 2006. Dissertação (Mestrado em Educação) - Pontifícia Universidade Católica de São Paulo, São Paulo, 2006.

HEIDEGGER, M. Ser e tempo. Petrópolis: Vozes; Bragança Paulista: Editora Universitária São Francisco, 2006.

LEÃO, E. C. Aprender e ensinar. In: LEÃO, E. C. Aprendendo a pensar. Petrópolis: Vozes, 1977.v. 1.p. 44-50.

MERLEAU-PONTY, M. Fenomenologia da percepção. 4. ed. São Paulo: WMF Martins Fontes, 2011.

RODRIGUES, N. F. A pátria de chuteiras. Rio de Janeiro: Nova Fronteira, 2013.

ROSA, J. G. Grande sertão: veredas. 19. ed. Rio de Janeiro: Nova Fronteira, 2001.

SCHLEIERMACHER, F. D. E. Hermenêutica: arte e técnica da interpretação. 7. ed. Petrópolis: Vozes, 2009.

SCHMIDT, L. Hermenêutica. Petrópolis: Vozes, 2014.

VAN MANEN, M. Phenomenological pedagogy and the question of meaning. In: VANDENBERG, D. (org.). Phenomenology and educational discourse. Durban: Heinemann Higher and Further Education, 1996. p. 39-64.

\section{SOBRE O AUTOR}

Ricardo Pedroza Vieira é doutor em filosofia pela Universidade Federal do Rio de Janeiro (UFRJ). Professor do Colégio Pedro II (CPII).

E-mail: ricardopvieira@gmail.com 
Conflitos de interesse: $\mathrm{O}$ autor declara que não possui nenhum interesse comercial ou associativo que represente conflito de interesses em relação ao manuscrito.

Financiamento: $\mathrm{O}$ estudo não recebeu financiamento.

Recebido em 28 de fevereiro de 2020

Aprovado em 4 de agosto de 2020 